\title{
ASO Author Reflections: The Volume-Outcome Association for Complex Cancer Surgery: A Rising Tide Lifts All Boats
}

\author{
Nabil Wasif, MD, MPH ${ }^{1}$ \\ Department of Surgery, Division of Surgical Oncology, Mayo Clinic Arizona, Phoenix, AZ
}

\section{PAST}

A cavalcade of studies over the last two decades has demonstrated the association of higher surgical volume with improved postoperative outcomes for complex surgeries. ${ }^{1}$ This has culminated in the "take the volume pledge," calling for limiting such operations to institutions and surgeons who meet a minimum threshold of case volume. ${ }^{2}$ Translating this into policy has proven problematic, with issues related to travel distance, disparities in access, and fragmentation of care preventing ready adaptation. Furthermore, postoperative mortality has continued to decline steadily due to overall improvement in postoperative care. How this changes the volume-outcome association in contemporary practice is relatively unknown. In our article, ${ }^{3}$ we test the hypothesis that the volume-outcome association is not static and has attenuated over time due to improved postoperative mortality in low- and medium-volume hospitals.

\section{PRESENT}

We show that the volume-outcome association for complex cancer surgery is dynamic rather than static. ${ }^{3}$ An overall improvement in postoperative mortality during the study duration is confirmed by our results. However, this improvement is differential in that it is more pronounced in low- and

This ASO Author Reflections is a brief invited commentary on the article "Contemporary Improvements in Postoperative Mortality after Major Cancer Surgery Are Associated with Weakening of the

Volume-Outcome Association," Ann Surg Oncol. 2019; 26: 2348-56.

(C) Society of Surgical Oncology 2019

First Received: 18 September 2019; Published Online: 30 September 2019

N. Wasif, MD, MPH

e-mail: wasif.nabil@mayo.edu medium-volume hospitals compared with high-volume hospitals. This leads to a narrowing of mortality differences between high- and low-, and especially high- and medium-volume hospitals. Medium-volume hospitals now have outcomes that are statistically no different from high-volume hospitals.

\section{FUTURE}

Our results suggest that the thresholds underpinning the "volume pledge" may need to be revised. If medium-volume hospitals have comparable outcomes to high-volume hospitals, then these thresholds could be set lower. Updated volumeoutcome analyses are needed to establish new thresholds in the "modern" era of surgery. Incorporating medium- as well as high-volume hospitals as part of a regionalization proposal may be a more pragmatic policy to implement. Moving beyond volume, structural and process measures associated with improved postoperative mortality in low- and medium-volume hospitals should be identified and disseminated.

DISCLOSURES The authors declare that they have no conflict of interest.

\section{REFERENCES}

1. Birkmeyer JD, Siewers AE, Finlayson EV, et al. Hospital volume and surgical mortality in the United States. N Engl J Med. 2002; 346(15):1128-37.

2. Urbach DR. Pledging to eliminate low-volume surgery. $N$ Engl $J$ Med. 2015; 373(15):1388-90.

3. Wasif N, Etzioni D, Habermann EB, Mathur A, Chang Y-H. Contemporary improvements in postoperative mortality after major cancer surgery are associated with weakening of the volume-outcome association. Ann Surg Oncol. 2019; 26:2348-56.

Publisher's Note Springer Nature remains neutral with regard to jurisdictional claims in published maps and institutional affiliations. 